\title{
Flavionavia Paesicorum, ¿Ceca Visigoda?
}

Alberto González García

UNIVERSIDAde De Vigo cuborg1985@gmail.com

Flavionavia Paesicorum, a visigoth mint?

Doctorando en Protección del Patrimonio.

El presente artículo se basa en la comunicación

homónima realizada por el autor en el VII Congreso

Internacional de Jóvenes Medievalistas: la reutilización

del pasado en la Edad Media

(Oviedo, I4-I6 de octubre de 2019).

ReCIBIDO: 2I-05-202I

EVALUADO Y ACEPTADO: 2I-09-202I

Territorio, Sociedad y Poder, No I6, 202I [Pp. 43-55] 
Resumen: El artículo trata de determinar la posible localización de la ceca visigoda de Pesicos, de la cual sólo se conservan dos monedas. Evaluamos, en primer lugar, las propuestas realizadas hasta la fecha y por qué consideramos que son incorrectas. Se discute también la propia naturaleza de la civitas Paesicorum, mostrando que probablemente no se correspondió a un centro urbano concreto. A continuación se explora la naturaleza de las emisiones monetarias visigodas, señalando su naturaleza eminentemente fiscal, y

ABSTRACT: This paper aims to determine the location of the Visigothic mint of Pesicos, of which only two coins remain. We first bring up to date proposals and explain why we consider them incorrect. The very nature of the civitas Paesicorum is also discussed, showing that it probably did not correspond to a specific urban center. Next, the nature of Visigoth monetary issues is explored, pointing out their eminently fiscal nature, as well as remarking that Pesicos' issues were part of remarcando que las emisiones de Pésicos formaron parte de un conjunto muy numeroso de pequeñas cecas, característico del noroeste hispano en el siglo viI. Dada la vinculación de estos talleres con élites locales, finalmente, exploramos la importancia de Flavionavia como centro aristocrático, concluyendo la probable adscripción de la ceca de Pésicos a esta ciudad.

Palabras clave: Pravia (Asturias); Reino Visigodo de Toledo; cecas visigodas; fiscalidad altomedieval.

a large amount of small mints, characteristic of the Spanish northwest in the 7th century. Because of the proven links between these workshops and local elites, we finally explore the importance of Flavionavia as an aristocratic center, concluding the probable adscription of the Pesicos mint to this city.

KeYwords: Pravia (Asturias); Visigothic Kingdom of Toledo; Visigothic mints; early medieval fiscality. 


\section{HISTORIOGRAFÍA DE LA CECA VISIGODA DE PESICOS}

La ceca visigoda de Pesicos es conocida tan sólo a través de dos únicos tremisses (fig. I) acuñados por los reyes Gundemaro (6IO-I2) y Sisebuto (6I2-2I), así como por la mención de esta localidad como iglesia dependiente de la diócesis de Astorga, tal como indica el Parochiale Suevum (X, Io). De esas dos monedas únicas, una se encuentra conservada en la colección lisboeta de la Casa Bancária Almeida, Basto \& Piombino \& Cia. (CNV 330 [tipo 197]; publicada por Batalha Reis, 1962), mientras que la otra, adquirida por el Museo Arqueológico Nacional en I9I2 (CNV 352 [tipo 246]; Mateu y Llopis, 1936: 38I [n. ${ }^{\circ} 321$ ]; Miles, 1952: $27 \mathrm{I}$ [n. ${ }^{\circ}$ 206]), desapareció junto con el resto de la colección de moneda visigoda de esa institución, incautada por el gobierno republicano en 1936 (Almagro Gorbea, 2008).

La relación de esta localidad con la tribu astur de los paesici mencionados por Plinio (III, 28 y IV, III) y Ptolomeo (II, 6, 5) ha sido siempre considerada evidente. Sin embargo, la ubicación exacta de este misterioso taller aún permanece como una cuestión abierta. La atribución al concejo de Pesoz fue propuesta hace más de un siglo por Beltrán Villagrasa (I913-I8: 165-I66) y mantenida durante décadas de forma inopinada. Ello subraya cuán sencillo es que se asiente en la historiografía la vinculación de una ceca a una localidad concreta a través de la mera repetición acrítica (e.g. Miles,
1952: 139-I40 y 27I; Batalha Reis, 1962: 22), sin explorar completamente los hechos u otras opciones.

Hubo de ser Sánchez de Arza (1985) quien señalara este error, pues el concejo de Pesoz no se encuentra en el territorio de los antiguos pésicos, sino enclavado en el correspondiente a sus vecinos galaicos los albiones, situados en la otra margen del Navia. Sin embargo, (Sánchez de Arza, 1985: 330), indicaba, por error, a los zoelas. ${ }^{1}$

Por su parte, Santos Yanguas y Vera García (I999a y b) propusieron el castro de Arganza (Tineo) como la auténtica civitas Paesicorum y por tanto la localización más probable de esta ceca. Vincularon sus efímeras emisiones a una presunta campaña de conquista bajo Gundemaro y Sisebuto, ya que San Isidoro de Sevilla afirmaba que este último monarca sometió a roccones y luggones y aquel se enfrentó a la rebelión de los ástures.

Finalmente, Ruth Pliego (2009: I4I), en su monumental monografía sobre la moneda visigoda, la situó de forma más imprecisa en las inmediaciones de Cangas del Narcea, siguiendo a Santos Yanguas y Vera García, pero sin notar que Arganza está en Tineo.

Hasta la fecha no se han producido nuevos avances a este respecto, lo que nos hace concluir el repaso historiográfico.

\footnotetext{
${ }^{1}$ Aunque antiguamente se los situó en el área eo-naviega, en la actualidad se admite que habitaron la región entre Braganza y Zamora, véase, por ejemplo, Olivares Pedreńo 2002.
} 


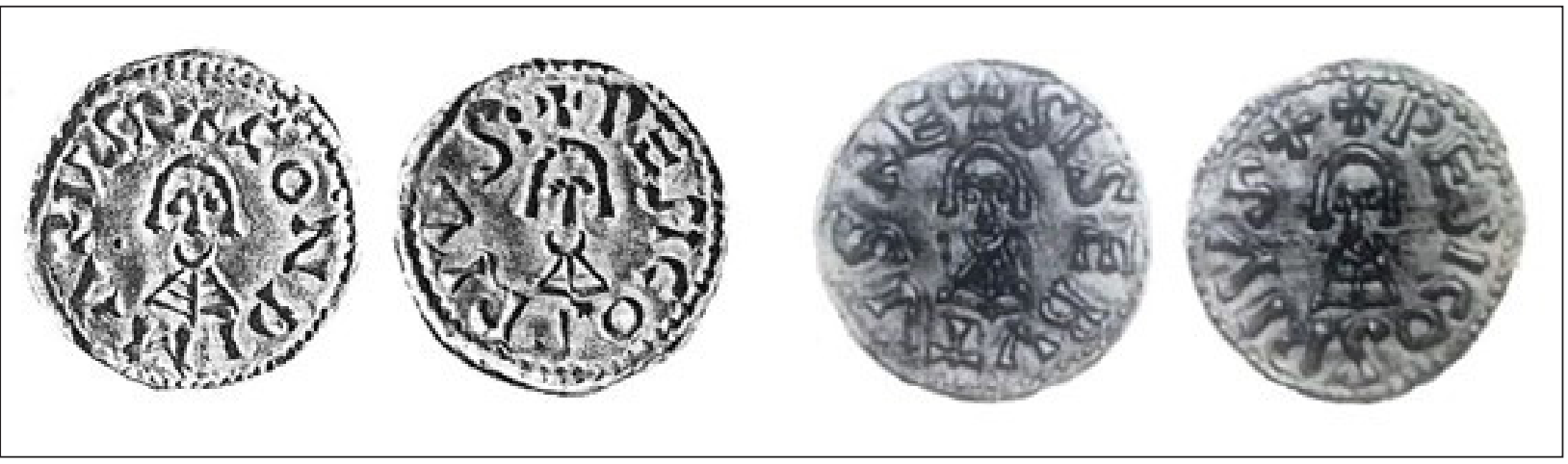

Fig. I. Trientes de Gundemaro (izquierda) y Sisebuto (derecha), únicos ejemplares acuñados en Pésicos. Triente de Gundemaro, I,52 g, I8 mm: A/ + GONDIMARVS R(ex). Busto de frente. R/ + PESICOS PIVS. Busto de frente (Colección de la Casa Bancária Almeida, Basto \& Piombino \& Cia., Lisboa). Triente de Sisebuto, I,45 g, I8 mm: A/ + SISEBVTVS RE(x). Busto de frente. R/ + PESICOS PIVS +. Busto de frente (Museo Arqueológico Nacional, Madrid; perdida).

\section{LA CIVITAS PAESICORUM}

Como hemos indicado, Santos Yanguas y Vera García (ig99a y b) basaron su identificación de la ceca de Pesicos con Arganza al postular la identidad hipotética de ese topónimo como la Civitas Paesicorum, y situarla en ese castro, al que el consideraron centro cívico y administrativo de los paesici. Se basaron en una inscripción allí localizada, interpretando las iniciales «C.P.» como Civitas Paesicorum (García Linares y Santos Yanguas, 1989), y en la mención a una Mansio Passacin en el Anónimo de Rávena (320, 17). A este respecto, seguían el juicio de Diego Santos (1977: 44), quien estableció la equivalencia de Passacin con la «capital» de este pueblo y la ceca visigoda.

Sin embargo, resulta extremadamente dudoso pensar que la Civitas Paesicorum fuera un enclave concreto, la cabecera del populus Paesicorum, el cual ocuparía un amplio territorio de Asturias occidental, en torno a los ríos Narcea, Pilońa, y el bajo Nalón. Contrariamente a lo afirmado por Santos Yanguas (1997: 417-4I8; 1998a: I25; Santos Yanguas y Vera García, I999b: 67-7I), las civitates del norte hispano no eran similares a los municipios. Vale la pena detenerse en esta cuestión.

En todo el norte hispano existen numerosos ejemplos de pueblos indígenas asimilados a civitates, sus asam- bleas a senados y sus caudillos a principes. Tal es el caso paradigmático de Herrera de Pisuerga, donde una célebre tésera hablaba del Senado, los cives y la civitas Maggavensium (García y Bellido, 1966). ${ }^{2}$

Por su parte, Plinio (Nat. Hist., III, I8 y 23-28) refería la existencia de múltiples civitates correspondientes no a lugares concretos, sino a pueblos. Así, Fernández Calo (2015) indicaba cómo las 293 civitates citadas por este autor coinciden exactamente con la suma de civitates en sentido estricto, populi y oppida que desglosó Plinio, lo que prueba que estas tres categorías se comprendían en las civitates en sentido amplio. Los historiadores griegos Ptolomeo (Geog., II, 6, 2I-48) y Apiano (Ibér. 55) hablaban de $\pi$ ódeıৎ, entre ellas la de los Paesici, siendo $\pi$ ó $\lambda$ is, como es lógico, equivalente al concepto latino de civitas.

De igual modo, Julio César (B. Hisp. 42) diferenciaba entre las instituciones indígenas hispanas (princeps, hospitium, ius gentium) y sus equivalentes romanas (magistratus, municipium, ius civile), evidenciando su carácter general (López Barja, I995-1996: 179). Parece claro que el objetivo de semejante organización, a pesar de conferir cierta autonomía local, era el control terri-

\footnotetext{
${ }^{2}$ En esta zona, casualmente, también contamos con otra ceca visigoda cuya vinculación a un punto concreto también es problemática (Pliego 2009: II6).
} 
torial, fiscal y militar de estas comunidades por parte de Roma, y su asimilación (Mangas Manjarrés, 1996: 54).

De ahí que se hiciera equivaler pueblos a civitates, y tal designación acabara en los textos de historiadores y geógrafos como los antedichos. A nuestro entender, estas civitates obedecerían más a una realidad administrativa o territorial que étnica. ${ }^{3}$

Esto es así por la práctica del abandono de poblados montañosos y de los oppida indígenas, forzada por el poder romano, y la deportación de los supervivientes para habitar en los valles vecinos o poblar otras zonas más alejadas. Fueron dinámicas habituales en Hispania durante toda la República Tardía y el naciente Imperio. A raíz de las Guerras Celtibéricas, las Guerras Sertorianas y las Guerras Cántabras de los siglos II y I a.C., tenemos constancia escrita de la confiscación y el reparto de territorios, el desplazamiento de poblaciones vencidas, así como la creación de nuevas ciudades por parte de los romanos; unas despoblaciones y repoblaciones bien documentadas en las fuentes escritas, que han sido confirmadas arqueológicamente (López Melero et al., 1984; Balboa, 1999; Pina Polo, 2004; Martínez Morcillo, 2016).

En el caso concreto de los ástures podemos mencionar, por ejemplo, la creación de un Forum Gigurrorum (Georres), en la actual comarca de Valdeorras (Orense). Una localidad que, a nuestro entender no por casualidad, fue también ceca visigoda (Pliego, 2009: I38-I39) e iglesia del Parroquial Suevo (IX, 6).

Es decir, esas civitates del norte hispano se correspondían con un territorio bajo el control de un pueblo, pero no se referían a una localidad concreta. No tendríamos, por tanto, un centro de población indígena convertido por los conquistadores en cabecera de un pueblo sometido.

No siendo excepcional el caso de los Paesici, debemos concluir, pues, que la civitas Paesicorum era el conjunto del populus y su territorio, y no una localidad concreta, lo cual, en nuestra opinión, desmonta per se la pretendida identificación de la ceca visigoda de Pesicos con Arganza.

\footnotetext{
${ }^{3}$ De igual modo, Gutiérrez González (2007: 28) recordaba que los nombres étnicos de las iglesias del Parroquial Suevo no deben «considerarse de forma simplista como un síntoma de arcaísmo indigenista ajeno a la romanización».
}

\section{LA NATURALEZA DE LAS EMISIONES MONETARIAS GODAS}

Corresponde, por tanto, responder a la cuestión de por qué se emitieron esas monedas, y tal vez ello nos oriente acerca del lugar más probable de localización de la ceca.

Como muestra el minucioso análisis de Ruth Pliego (2009: 97-I53), no fueron más de diez las cecas que emitieron de forma casi continua: tres en la Bética, Corduba, Eliberri (Monte de Elvira, Granada) e Ispali (Sevilla); una en la Carthaginense, Toleto; dos en la Lusitania, Egitania (Idanha-a-Velha, Beira Baxa, Portugal) y Emerita (Mérida); dos en la Tarraconense, Cesaraugusta (Zaragoza) y Tarracona (Tarragona); y sólo una en la en la Narbonense, Narbona.

En cambio, Pésicos, con sus dos únicas monedas conocidas, formó parte de un conjunto de cecas del noroeste hispano con una escasísima producción. La cual, con excepción de Lugo, Braga y Tuy, se concentra en exclusiva a comienzos del siglo VII (Pliego, 2009: I28-I46 y I5O-I5I).

Es difícil determinar a qué se debió la existencia de tantas cecas con acuñaciones esporádicas en lugares tan remotos, sin la importancia económica de las grandes ciudades donde se localizaban los principales talleres monetarios visigodos.

Diversos autores (e.g. Mateu Llopis, 1944; García Moreno, I974: II3-II4; I982: 333-345; I989: 28I-282; Barral i Altet, 1976: 83-86; Diego Santos, 1977: 246248; López Sánchez, 2009: I79-I83; Kurt, 2020: 2II-220) consideraron que estas emisiones tuvieron una finalidad eminentemente militar, en relación con la financiación de las campañas militares de los visigodos contra el reino suevo y los pueblos del norte. Las monedas de Pésicos indicarían, en consecuencia, el proceso militar de la conquista y la implantación del dominio visigodo sobre los astures occidentales

Por su parte, Crusafont (1994: 78) apuntó la posibilidad de que estos talleres esporádicos realizaran emisiones conmemorativas. Ruth Pliego (2009: 192-I93 y 215-230) también puso en cuestión la relación de la 
moneda con las campańas militares y la idea de una ceca volante para el pago de tropas, para, a continuación, analizar la posibilidad de su uso fiscal y rechazar el comercial. Una naturaleza fiscal postulada, también, por otros especialistas como Hendy (1988), aunque haya sido matizada, por ejemplo, por Barral (1976) y Metcalf (I986 y I988), quienes defendían una economía comercial ampliamente monetizada (véase Santiago, 20II, para estas cuestiones).

Nuestra opinión es que constituye un error metodológico grave asociar mecánicamente la acuñación de moneda con conquista armada y el paso de ejércitos en campaña, más aún cuando Asturias ya había sido sometida por Leovigildo (572-86). Las expediciones de Gundemaro y Sisebuto difícilmente pueden considerarse otra cosa más que la represión de rebeliones locales, cuya entidad y trascendencia fueron relativamente escasas. Gutiérrez González (2010: 74) ya indicó, con gran perspicacia, que «no todas las monedas y cecas coinciden con campañas militares, sólo las de Pesicos serían coetáneas con el sometimiento de astures y roccones o luggones por Sisebuto».

En efecto, las recientes investigaciones de Díaz Martínez (2004), Castellanos y Martín Viso (2005), Castellanos (2006), Retamero (20II) y Sánchez Pardo (2014a y b) han demostrado la importancia capital de los pequeños centros mineros, administrativos, militares y eclesiásticos de naturaleza local y aristocrática en todo en noroeste hispano. Heredados en su inmensa mayoría de época sueva, coinciden plenamente con las cecas visigodas. A nuestro entender, la correlación de estas emisiones monetarias con la existencia de élites locales ha sido demostrada más allá de cualquier duda razonable por estos autores, y no ha sido refutada. ${ }^{4}$

\footnotetext{
${ }^{4}$ Kurt (2020: 217 [n. 666]) se limita a decir que la vinculación con centros mineros es sugestiva pero inconcluyente y omite cualquier mención a centros aristocráticos. Para este autor, las acuńaciones de Recaredo con la leyenda VICTOR demostrarían que eran la culminación de una campańa militar algo que extrapola inopinadamente a acuńaciones del siglo VII (Kurt 2020: 2II-220). Kurt tampoco aprecia que, según esa teoría, primero hay que haber ganado, lo cual excluye la posibilidad de una ceca volante para financiar al ejército y apuntala nuestra idea de acuńaciones posteriores a acciones militares, como parte de la sumisión de élites locales. Al tratar del uso de la moneda, lo estima fundamentalmente fiscal, aunque admite el comercial, y ni siquiera
}

Por añadidura, el ejército visigodo no era un ejército mercenario como el romano, retribuido en moneda. Muy a la contra, los hombres libres y la aristocracia terrateniente prestaban servicios de armas a la Monarquía toledana, aportando sus contingentes de dependientes personales y reclutando levas locales (Isla Frez, 20IO). De tal modo, las necesidades de moneda en plena campaña eran ínfimas. 5

Dada la naturaleza fundamentalmente fiscal de la moneda visigoda (la cual, por supuesto, no excluye los intercambios comerciales) y la inexistencia de un ejército mercenario, creemos necesario descartar la asociación falaz de cecas pequeñas con el abastecimiento de moneda a ejércitos en campaña.

En cambio, sí que se puede postular que esas acuñaciones corresponden a la sumisión de los vencidos y la regularización de la fiscalidad como consecuencia de la represión posterior al fracaso de una rebelión, sofocada manu militari o de forma pactada. Los sometidos tenían que aceptar que el nuevo gobernante acuńara su oro como moneda visigoda y se quedara con un pequeño porcentaje del metal precioso en concepto de señoreaje durante el proceso.

El control de la recaudación de impuestos por parte de las aristocracias locales les permitía fungir como «bisagra entre sus comunidades y el poder central (suevo, visigodo o franco, y más tarde musulmán), basculando entre la integración política y aceptación fiscal o la rebelión e insumisión tributaria», en acertada expresión de Gutiérrez González (20I0: 76). En efecto, cuando se produjo la conquista musulmana de la Hispania goda, fue prioridad de los conquistadores la «sustitución absoluta del numerario visigodo» por el suyo propio, mediante la fundición y reacuñación masiva (Conde, I8I7, I9; cit. por Martín Escudero 2005: 36; Canto, 20II: I35).

menciona al ejército (Kurt 2020: 26I-272).

${ }^{5}$ Existen muchas referencias en el Liber Iudiciorum y en las actas conciliares toledanas a la cuestión de las levas y el servicio de armas, demasiado numerosas como para citarlas aquí. Es célebre también la inscripción funeraria del noble Oppila, hallada en Villafranca (Córdoba), que indicaba cómo este prócer visigodo halló la muerte en 642 combatiendo a los vascones, al frente de sus clientes, transportando un cargamento de flechas (Vives 1942: 90-9I [n. $\left.\left.{ }^{\circ} 287\right]\right)$ 
Las políticas de pacto de la Monarquía visigoda con las élites locales incluían un firme control del territorio a través de la fiscalidad y la concesión a los terratenientes del privilegio de recaudar impuestos, que debían satisfacerse en la moneda regia. Y para ello era necesario reacuñar el metal precioso a nivel local de las áreas incorporadas al reino, ya fuera tras una conquista o tras una rebelión. De igual modo, la dinámica de confiscación del patrimonio fundario de los rivales políticos y reparto de su usufructo entre los aliados fue una constante del reino toledano, que se iniciaba y finalizaba con cada ascenso al trono (Díaz Martínez, 20I2). Ni siquiera cabría atribuir un carácter indigenista o independentista a estas revueltas locales del noroeste hispano y las consecuentes reacuñaciones de numerario, ya que la inestabilidad política y las sublevaciones fueron endémicas en todo el reino toledano, sin distingos de mayor o menorromanización.

Por tanto, estimamos que, antes que sostener una excepcionalidad inexplicable e inexplicada sobre la naturaleza militar del numerario que aquí nos ocupa, habría que pensar en que no hay excepción: las reducidas emisiones de Pésicos corresponden a la sumisión fiscal de un centro aristocrático local, no al abastecimiento de moneda a ejércitos en marcha. Y es lógico, por tanto, que su cuantía fuera escasa, dada la relativa pobreza del territorio.

Asimismo, la localización de los roccones y los luggones de Sisebuto dificulta mucho la interpretación militar, y lo mismo puede decirse de los genéricos ástures alzados bajo Gundemaro. Que no por obligación hubieron de ser los transmontanos, sino más probablemente los cismontanos. Recordemos que Pésicos no emitió de forma aislada, sino de forma coetánea a varias cecas. Pues bien: la mayoría de las acuñaciones realizadas en territorio de los ástures por parte de los monarcas que los combatieron a comienzos del siglo viI, Gundemaro (6IO-I2) y Sisebuto (6I2-2I), se sitúan justamente en los límites occidentales de la Asturia Cismontana con la Gallaecia. Concretamente, las cecas de Georres (Valdeorras), Senabria (Puebla de Sanabria), Calapa, Bergantia y Vallearitia acuñaron bajo ambos soberanos;
Pincia y Bergio también bajo Sisebuto, junto con otras próximas, tanto en la meseta, tal es el caso de Semure (Zamora) como en Galicia. Territorios de clara romanización donde no se postula la existencia de sublevaciones indigenistas.

Esto coincide con la tradicional identificación de los roccones no con los luggones transmontanos, sino con los araucones o aregenses, que, según Juan de Bíclaro (Chron. 35), tenían un principado independiente y fueron sometidos en 575 por Leovigildo, quien capturó al senior loci Aspidio. Serían los mismos roccones a los que combatió el rey suevo Miro pocos años antes, en 572 (Juan de Bíclaro, Chron. 2I). Este pueblo habitaría en los límites occidentales de la diócesis de Astorga, como sostuvieron diversos autores (Torres López, 1963: IOI; Campos, I960: I23; Thompson, I969: 62). ${ }^{6}$ Algo hasta cierto punto avalado por el Parroquial Suevo (IX), que atribuía a la diócesis auriense determinadas iglesias fronterizas de la asturicense (Geurros; Pincia; Cassauio; Uerecanos; Senabria; Calapacios), frente a la teoría de Diego Santos (I979: 23-26), que los identificaba con los luggones transmontanos.

Por tanto, estimamos válido concluir que las emisiones godas de Pésicos nada tuvieron que ver con la financiación de una campaña militar en la Asturia Transmontana, sino con el sometimiento de las élites locales al término de las rebeliones de ambas Asturias, la Transmontana y la Cismontana. Esta interpretación es coherente tanto con las fuentes numismáticas y escritas, como con la localización de otras cecas coetáneas del Noroeste.

Por supuesto, esta conclusión contradice en gran medida las ideas de los profesores Barbero y Vigil (1974 y I978: 296-302), quienes postularon que la región cántabro-astur que no había sido dominada de forma efectiva por los reyes visigodos de Toledo. Más que intentar buscar un acomodo (sumisiones nominales, etc), creemos que deben desestimarse sus postulados, toda vez que ya han sido refutados in extenso por Besga Marroquín (2000) y Menéndez Bueyes (200I).

\footnotetext{
${ }^{6}$ Por su parte, Piel (1948: 36), señaló lo habitual del nombre Aspidius en esa zona.
} 


\section{FLAVIONAVIA COMO CENTRO ARISTOCRÁTICO}

Una vez determinada la naturaleza fiscal y aristocrática de las emisiones de Pésicos, corresponde determinar la existencia de un centro aristocrático de entidad, es decir, la localización más probable para el taller monetario.

A la hora de analizar el numerario visigodo, tiende a olvidarse la importancia capital de que Pesicos no sólo fuera una ceca, sino que, como indicamos con anterioridad, también se tratara de una ecclesia asturicense. Figura en el Parroquial Suevo (X, Io), que se relaciona con el Concilio de Lugo de 569. David (1947: 67-68) garantizó la autenticidad de ese documento y lo dató hacia 572-82. Isla Frez (1992: 2I), por su parte, adelantó esta última fecha a 579-80. Ello es indicativo de la antigüedad de esta iglesia, la cual, como mínimo, se remontaría justo a ese siglo, el VI.

La cristianización y la existencia de construcciones religiosas significan casi siempre la presencia de élites aristocráticas romano-godas. La evolución del territorio de Pésicos entre las épocas antigua y altomedieval ha sido objeto de la atención de Fernández Mier (2002) y Muñiz López (2006: 87-89), estimando la primera la pervivencia de un sistema territorial prerromano. De nuevo, se aprecia continuismo antes que ruptura.

¿Dónde, en territorio de los pésicos, tenemos constatada esa presencia de élites y de una iglesia como tal antes de los reinados de Gundemaro y Sisebuto? Parece evidente que sólo en Flavionavia. Desde luego no hay constancia de ninguna iglesia tardoantigua en Arganza.

Flavionavia fue citada por Ptolomeo (II, 6, 4), sin que figure en ninguna otra fuente antigua o medieval. $\mathrm{Su}$ discutida ubicación geográfica tiende aceptarse hoy día en la desembocadura del Nalón, concretamente en la localidad de Santianes de Pravia y su entorno (González y Fernández-Valles, I953 y 1976; Santos Yanguas, 1997 y 1998a; Fernández Ochoa, 2002).

La arqueología también ha demostrado en los últimos ańos la importancia de la presencia romana y visigoda en torno a Pravia, lo cual contraría, una vez más, la idea del indigenismo y de que los visigodos nunca habrían llegado a controlar totalmente una Asturias trans- montana siempre rebelde. Aunque aristócratas locales se alcen con el poder una vez desaparecido el aparato estatal romano, no cabe asimilarlos a jefes indígenas tras siglos de dominación romana.

Contamos, en primer lugar, con la importante evidencia proporcionada por la simple existencia de la propia iglesia, con sus elementos prerrománicos, que datan del s. IX, y decoración de clara tradición visigoda (Fernández Conde y Santos del Valle, 1987; García de Castro Valdés, I995: passim; Caballero Zoreda y Rodríguez Trobajo, 20I0: II-90 y I9I-203). Por añadidura, se han hallado niveles de enterramiento anteriores a la construcción de la actual iglesia (Fernández Conde et al., 1992), lo que, hasta cierto punto, permite confirmar lo afirmado por el Parroquial Suevo.

Si seguimos la propuesta de historia social de la arquitectura prerrománica asturiana de Quirós Castillo y Fernández Mier (20I2), es inevitable pensar en una aristocracia capaz de disponer de considerables recursos materiales y acceso a una estructura artesanal suficiente como para producir obras de cierta entidad. Lo cual posiblemente superara las posibilidades locales y conllevara la llegada de trabajadores especializados foráneos.

Santianes de Pravia se encuentra, asimismo, cerca de los castros de San Martín y Doña Palla, de los restos de villas romanas en La Magdalena de la Llera (Gorges, 1979: 333) y la propia Pravia, y en la estación viaria o villa de Las Murias de Doriga, Salas (Estrada García, 2007), las termas de Valduno (Estrada García 20I4), o la inscripción romana de Los Cabos (Santos Yanguas, I998b).

Gutiérrez González (2010: 58) indicaba que la antigua Flavionavia no tuvo por qué ser un núcleo urbano concentrado, y que pudo tratarse de una civitas con cabecera polinuclear. Si quitamos de la ecuación la equívoca concepción de la civitas Paesicorum como una localidad determinada y entendemos que Flavionavia no era una civitas, podemos comprender mucho mejor su naturaleza como un centro aristocrático probablemente disperso.

Tampoco puede olvidarse su cercanía relativa a otros grandes núcleos de poder local en época tardoantigua 
en el área central asturiana: se encuentra a 35 kilómetros Lucus Asturum, a 45 de Gijón y a I9 del castillo de Gauzón.

Desde el punto de vista monetario en la zona, en primer lugar, tenemos el hallazgo de un tremís de Recaredo (588-6or) en las excavaciones del casillo de Gauzón, aunque se trate de una moneda perforada para servir como colgante, lo que puede ser indicativo de su desmonetización (Muñiz López y García ÁlvarezBusto, 20I4: 220). Cabe recordar también que hay otros hallazgos descontextualizados de moneda visigoda en Asturias, siendo el más importante un tesoro de al menos ocho monedas en Oviedo (1958), con piezas de los reyes Chindasvinto y Recesvinto, datado en torno a 653 (Barral, 1976: 124; Pliego, 2009: 257).

Incluso se ha propuesto la posibilidad de que algunos nummi tardorromanos -hallados por toda el área central de Asturias- se mantuvieran en circulación durante el período visigodo, si bien en una economía poco monetizada (Menéndez Bueyes, 200I: I86-I88; 2002; Menéndez-Bueyes y Carriles García, 20II).

La importancia de Pravia como centro local de poder económico, religioso y administrativo en época visigoda también explicaría el que fuera elegida capital del reino asturiano bajo el reinado de Silo (774-83), quien ascendió al trono a la muerte de Aurelio (768-75) en mor de su matrimonio con Adosinda, hermana del rey Fruela, asesinado en 768 (Albeldense XV, 6; Rotense I4). Se ha considerado que Pravia fue seleccionada por tratarse del centro del poder fundario del nuevo rey o de su esposa, además de superar el remoto localismo de Cangas y hallarse más cercana a Galicia, incorporada por este monarca al naciente reino asturiano, y evidentemente (González y Fernández-Valles, 1979; Fernández Conde y Santos del Valle, ı988; Gutiérrez González, 2007, 40-4I).

Sin embargo, también se ha llamado la atención sobre la importancia de Pravia como un centro de poder aristocrático preexistente, que se remontaría, como mínimo, a la época visigoda y romana (Fernández et al., 2009: 25-26; Gutiérrez González, 2010: 58). Todo ello cual nos permite incidir en las raíces profundas de las estructuras que permitieron el nacimiento y desa- rrollo de la Monarquía Asturiana, que nos retrotraen, una vez más, a estructuras romanas y godas, antes que indígenas, como postularon los profesores Besga Marroquín (2000) y Menéndez Bueyes (200I).

De Silo sabemos que tuvo paz con los musulmanes « $o b$ causam matris» (Albeldense XV, 6), una expresión harto imprecisa, que está abierta a múltiples interpretaciones. Sin embargo, si pensáramos en que su familia materna poseía importancia y predicamento en el territorio bajo dominio musulmán, resulta interesante comprobar que el peculiar cognomen latino Silo (nunca Silus, ni en las crónicas asturianas ni en el célebre documento del año 775), que significa «chato» o «romo», aparece de forma muy destacada en la zona de los ástures cismontanos. Concretamente en la célebre tésera de hospitalidad de los zoelas, datada en 27 d.C. (CIL II, $2633=$ IRPLe $318=$ EAstorga 86 = ILS 6IOI $=$ HEpOl 8444), donde se menciona a un tal L. Domitius Silo, de Asturica. También contamos con otros testimonios epigráficos esparcidos por el noroeste hispano que apuntan al paso, y tal vez al establecimiento de itálicos, lo que podría explicar su condición de notables locales en época romana, postromana y emiral, así como su afianzamiento y eventual vinculación matrimonial con la casa real asturiana.

\section{CONCLUSIONES}

Las localizaciones propuestas de forma sucesiva para la ceca visigoda de Pésicos no han sido argumentadas con la suficiente solidez, basándose en la toponimia, en una evidencia material muy limitada y discutible, y en una conceptualización errada de las civitates étnicas del norte hispano como si fueran centros urbanos.

Además, se han atribuido a estas emisiones una vinculación con la financiación de campañas militares que difícilmente puede sostenerse, dada la naturaleza fiscal de la moneda visigoda y que sus ejércitos, en su inmensa mayoría, no eran remunerados con moneda.

Los análisis geohistóricos de las cecas visigodas del norte peninsular han demostrado su correspondencia casi exacta con centros aristocráticos e iglesias preexistentes, documentadas en el Parroquial Suevi. Así pues, 
la conclusión es que Pésicos no es una excepción, sino que muy probablemente también siguiera este patrón.

Siendo Flavionavia el centro aristocrático y religioso más destacado que podemos documentar con cierta seguridad en el territorio de la civitas Paesicorum a comienzos del siglo viI (con la suficiente importancia como para ser capital de la monarquía asturiana durante un breve período), es más lógico adscribir las acuñaciones de moneda visigoda en Pésicos a esta localidad, si bien es una cuestión que sigue abierta, y podrá confirmarse o falsarse en el futuro. 


\section{BIBLIOGRAFÍA}

Almagro Gorbea, Martín (2008): «El expolio de las monedas de oro del Museo Arqueológico Nacional en la Segunda República española», Boletín de la Real Academia de la Historia, 205-I, p. 7-72.

Balboa de Paz, José Antonio (I999): «Un edicto de Augusto hallado en El Bierzo", Revista de Estudios Bercianos, 25, p. 44-53.

Barbero de Aguilera, Abilio, y Vigil Pascual, Marcelo (1974): Sobre los orígenes sociales de la Reconquista, Barcelona, Ariel.

Barbero de Aguilera, Abilio, y Vigil Pascual, Marcelo (i978): La formación del feudalismo en la Península Ibérica, Barcelona, Crítica.

Barral i Altet, Xavier (1976): La circulation des monnaies Suèves et Visigothiques. Contribution à l'histoire économique du royaume visigot (Beihefte der Francia 4), Múnich, Artemis Verlag.

Batalha Reis, Pedro (1962): «Triente inédito de Gundemaro cunhado em Pésicos», Numisma. I2, p. 17-24.

Beltrán Villagrasa, Pío (I913-I918): «Las monedas visigodas acuñadas en la Suevia espańola. Diócesis de Iria, Lucus, Aurense, Tude y Asturica», Boletín de la Comisión Provincial de Monumentos de Orense, 5, p. 8I-89, 97-IO4, II3-I2O, I29-I35, I45-I52 y I6I-I74.

Besga Marroquín, Armando (2000): Orígenes hispano-godos del Reino de Asturias, Oviedo, Real Instituto de Estudios Asturianos.

Caballero Zoreda, Luis, y Rodríguez Trobajo, Eduardo (2010): «Las iglesias asturianas de Pravia y Tuñón», en Arqueología de la arquitectura (Anejos de AEspA, 54), Madrid, CSIC.

Campos Ruiz, Julio (1960): Juan de Biclaro obispo de Gerona, su vida y su obra, Madrid, CSIC.

Canto García, Alberto (20II): "Las monedas y la conquista», Zona arqueológica, I5-I (Ejemplar dedicado a: 7II, arqueología e historia entre dos mundos), p. I35-I46.

Castellanos, Santiago (2006): «Ofensivas aristocráticas y articulación política en el norte hispano post-romano", en Espinosa, Urbano, y Castellanos, Santiago (eds.), Comunidades locales y dinámicas de poder en el norte de la Península Ibérica durante la Antigüedad Tardía, Logroño, Universidad de La Rioja, p. I4I-I64.

Castellanos, Santiago, y Martín Viso, Iñaki (2005): "The Local Articulation of Central Power in the North of the Iberian Peninsula", Early Medieval Europe, I3, p. I-42 (http://dx.doi.org/Io.IIII/j.I4680254.2005.00147.x).

Conde, José Antonio (I817): Memoria sobre la moneda arábiga y en especial sobre la acuñada en Espańa, por los príncipes musulmanes leída en la Real Academia de la Historia en junta del 2I de julio de I804, Madrid, Real Academia de la Historia.

Crusafont i Sabater, Miquel (1994): El sistema monetario visigodo: cobre y oro, Barcelona, Asociación Numismatica Española.

David, Pierre (1947): «L'organisation ecclesiastique du Royaume Suève au temps de Saint Martin de Braga», en David, Pierre, Études Historiques sur la Galice et le Portugal du vi au xir siécle, Coimbra, Livraria Portugália, p. I-II8.

Díaz Martínez, Pablo de la Cruz (2004): «Acuñación monetaria y organización administrativa en la Gallaecia tardoantigua», Zephyrvs, 57, p. 367-375 (https://rca.usal.es/index.php/o514-7336/article/view/5413).

Díaz Martínez, Pablo de la Cruz (20I2): «Confiscations in the Visigothic reign of Toledo. A political instrument», en Porena, Pirefrancesco, y Rivière, Yann (eds.), Expropiations et consfiscations dans les royaumes barbares.
Une approche regionales (Collection de l'École Française de Rome 470), Roma, École Française de Rome, p. 93-II2.

Diego Santos, Francisco (1977): Historia de Asturias, vol. III. Asturias romana y visigoda, Vitoria, Ayalga.

Diego Santos, Francisco (1979): «De la Asturias sueva y visigoda», Asturiensia Medievalia, 3, p. 17-60.

Estrada García, Rogelio (2007): «Estudio de la vertiente meridional del yacimiento romano de Las Murias (Doriga, Salas)», en AA.VV., Excavaciones arqueológicas en Asturias, 1999-2002, Oviedo, Servicio de Publicaciones del Principado de Asturias, p. 323-327.

Estrada García, Rogelio (20I4): «Baños de época romana de Santa Eulalia de Valduno (Las Regueras)», en León Gasalla, Pablo (coord.): Intervenciones en el patrimonio cultural asturiano 2007-2014, Siero, Consejería de Educación, Cultura y Deporte, p. I25-160.

Fernández Calo, Martín (2015): «Plinio, o Parroquial Suevo, e a evolución estrutural do poder local galaico na Antigüidade», Gallaecia, 34, p. 175-207 (нттрS://revistas.usc.gal/index.php/gallaecia/article/view/2796).

Fernández Conde, Francisco Javier, y Santos del Valle, M.C. (1987): «El visigotismo de la corte de Pravia: testimonios arqueológicos», en AA.VV. Arqueología Medieval Espańola (Actas del II Congreso), Madrid, Comunidad de Madrid, p. 393-403.

Fernández Conde, Francisco Javier, y Santos del Valle, M.C: (1988): «La corte de Pravia: fuentes documentales, cronísticas y bibliográficas», Boletín del Instituto de Estudios Asturianos, I25, p. 59-84.

Fernández Conde, Francisco Javier, Alonso Alonso, Gabino Arcadio, y Argǘllo MenéndeZ, José Jorge (I992): «Informe excavaciones en Santianes de Pravia», en AA.VV., Excavaciones arqueológicas en Asturias, 1987-90, Oviedo, Servicio de Publicaciones del Principado de Asturias, p. I89-I9I.

Fernández Conde, Francisco Javier, Gutiérrez González, José Avelino, Fernández Mier, Margarita, Suárez Álvarez, María Jesús y Arias PÁramo, Lorenzo (2009): «Poderes sociales y políticos en Asturias. Siglos VIII-X», en Fernández Conde, Francisco Javier, y

Fernández Mier, Margarita (2002): «Territorialidad y poblamiento: el occidente de Asturias en época de la monarquía asturiana», en AA.VV., La época de la Monarquía Asturiana: actas del simposio celebrado en Covadonga (8-Io de octubre de 200I), Oviedo, Real Instituto de Estudios Asturianos, p. 43-62.

García y Bellido, Antonio (I966): «Tessera hospitalis del año I4 de la era hallada en Herrera de Pisuerga», Boletín de la Real Academia de la Historia, I59, p. I49-166.

García de Castro Valdés, César (I995): Arqueología Cristiana de la Alta Edad Media en Asturias, Oviedo, Real Instituto de Estudios Asturianos.

García de Castro Valdés, César (coords.), Symposium Internacional Poder y Simbología en Europa, siglos vili-x [Actas del Symposium INTERNACIONAL CONVOCADO EN OVIEDO, 22-27 DE SEPTIEMBRE DEL 2008] (Territorio, sociedad y poder, anejo No 2), Oviedo, Trea, pp. il-30. García Linares, Antonio y Santos Yanguas, Narciso (1989): «Nueva lápida romana hallada en Arganza (Tineo, Asturias)», Memorias de historia antigua, IO, p. I5I-162.

García Moreno, Luis Agustín (I974), «Estudios SObre La ORganizaCión administrativa del reino visigodo de Toledo", Anuario de Historia del Derecho Español 44, P. 5-I55

(нттрs://www.boe.es/publicaciones/anuarios_derecho/articulo. php?id=ANU-H-1974-I0000500I56). 
García Moreno, Luis Agustín (I982): «Cecas visigodas y sistema económico», en Palol Salells, Pere de (dir.), II Reunió d'arqueologia paleocristiana hispànica (IX Symposium de Prehistòria i Arqueologia Peninsular), Montserrat, 2-5 novembre 1978, Barcelona, Institut d'Arqueologia i Prehistòria, p. 333-345. GonZÁlez y Fernández-Valles, José Manuel (1953): «Flavionavia, antigua población de los Paésicos», Boletín del Instituto de Estudios Asturianos, 28 , p. 32-45.

GonzÁlez y Fernández-Valles, José Manuel (1976): Miscelánea Histórica Asturiana (Prehistoria, Época Romana, Medioevo y Época Moderna), Oviedo, Imp. Gofer, p. 205-208.

GonzÁlez y Fernández-Valles, José Manuel (1979): «Pravia, capital del reino asturiano", Asturiensia Medievalia, 3, p. 87-IO4.

Gorges, Jean-Gérard (1979): Les villas hispanorromaines. Inventaire et problématique archéologiques (Publications du Centre Pierre Paris 4), París, De Boccard.

Gutiérrez GonZÁlez, José Avelino (2007): «La formación del territorio de Asturias en el período de la monarquía asturiana», en AA.VV. Enciclopedia del Prerrománico en Asturias, Oviedo, Fundación Santa María la Real, v. I, p. 19-56.

Gutiérrez GonZÁlez, José Avelino (20I0): «Arqueología tardoantigua en Asturias. Una perspectiva de la organización territorial y del poder en los orígenes del Reino de Asturias», en Ruiz de la Peña, Juan Ignacio, y Camino Mayor, Jorge (eds.), La carisa y la mesa: causas políticas y militares del origen del Reino de Asturias, Oviedo, Asociación de Amigos de la Carisa, p. 52-83.

Hendy, Michael F. (1988): "From Public to Private: The Western Barbarian Coinages as a Mirror of the Désintégration of Late Roman State», Viator, I9, p. 49-59.

Isla Frez, A. (1992): La sociedad gallega de la Alta Edad Media, Madrid, CSIC.

Isla Frez, A. (20Io): Ejército, sociedad y política en la Península Ibérica entre los siglos VII y XI, Madrid, CSIC.

Kurt, A. (2020): Minting, State, and Economy in the Visigothic Kingdom: From Settlement in Aquitaine through the First Decade of the Muslim Conquest of Spain (Late Antique and Early Medieval Iberia), Ámsterdam, Amsterdam University Press.

López Barja de Quiroga, Pedro Manuel (1995-1996): Testimonia Antiqua Hispaniae, Studia Historica, Historia Antigua, I3-14, p. 165-179 (http:// hdl.handle.net/10366/73399).

López Melero, Raquel, J. L. Sánchez Abal, José Luis, y García JiméNEZ, SANTiago (1984): «El bronce de Alcántara. Una deditio del ro4 a.C.», Gerión, 2, p. $265-323$ (https://revistas.ucm.es/index.php/GERI/article/ view/GERI84841IO265A/o).

Mangas Manjarrés, Julio (1996): Aldea y ciudad en la antigüedad hispana, Madrid, Arco Libros.

Martín Escudero, F. (2005): El tesoro de Baena: reflexiones sobre circulación monetaria en época omeya, Madrid, Real Academia de la Historia.

Martínez Morcillo, José Antonio (20I6): «Asalto de ciudades durante la República Romana (200-167 a.C.): esclavización de supervivientes en contextos de guerra», Gerión, 34, p. I69-188 (https://revistas.ucm.es/index.php/GERI/article/view/53739).

Menéndez Bueyes, Luis Ramón (200I): Reflexiones críticas sobre el origen del reino de Asturias, Salamanca, Universidad de Salamanca.

Menéndez Bueyes, Luis Ramón (2002): «Civitas christiana versus núcleos de poder: La ciudad post-romana en el Reino de Asturias», Studia Históri- ca. Historia Antigua, 20, p. 282-289 (https://rca.usal.es/index.php/o2132052/article/view/6162/6183).

Menéndez-Bueyes, Luis Ramón, y Carriles García, Adriana (20II): «Fiscalidad y Poder entre la Tardoantigüedad y la Alta Edad Media en un reino postgermánico: El Reino de Asturias (Período Formativo, siglos V-VIII)», en Díaz Martínez, Pablo de la Cruz, y Martín Viso, Ińaki (eds.), Between Taxation and Rent. Fiscal Problems From Late Antiquity To Early Middle Ages / Entre el Impuesto y la Renta. Problemas de la Fiscalidad Tardoantigua y Altomedieval, Bari, Edipuglia, p. 271-304.

Mateu y Llopis, Felipe (1936): Catálogo de las monedas previsigodas y visigodas del Gabinete Numismático del Museo Arqueológico Nacional, Madrid, Museo Arqueológico Nacional.

Metcalf, David M. (1986): "Some Geographical aspects of Early Medieval Monetary Circulation in the Iberian Peninsula", en Gomes Marques, Mário, y Crusafont i Sabater, Miquel (eds.): Problems of Medieval Coinage in the Iberian Area, II, Avilés, Sociedad Numismática Avilesina, p. 313-315;

Metcalf, David M. (1988): "For What Purposes Were Suevic and Visigothic Tremisses Used? The contribution of topographical analysis, illustrated by some comments on single finds from the Alentejo, and on the mint of Elvora”, en Gomes Marques, Mário, y Metcalf, David M. (eds.), Problems of Medieval Coinage in the Iberian Area, III, Santarem, Sociedade Numismática Scalabitana/Instituto de Sintra, p. 15-34.

Miles George C. (1952): The Coinage of the Visigoths of Spain. Leovigild to Achila II, Nueva York, American Numismatic Society.

Muñız López, IvÁn (2006): «La formación de los territorios medievales en el oriente de Asturias (Siglos viII al XII)», Territorio, Sociedad y Poder, I, p. 79-I28 (http://hdl.handle.net/1065I/45548).

Muñiz López, Iván, y García Álvarez-Busto, Alejandro (20I4): «El castillo de Gauzón en la Antigüedad Tardía. Una fortificación de la Asturias transmontana en época del reino visigodo», en Catalán Ramos, Raúl, Fuentes Melgar, Patricia, y Sastre Blanco, José Carlos (coords.), Las fortificaciones en la tardoantigüedad. Élites y articulación del territorio (siglos V-VIII d.C.), Madrid, La Ergástula, p. 215-228.

Olivares Pedreño, Juan Carlos (2002): «El dios Aernus y los Zoelas», Iberia: Revista de la Antigüedad, 5, pp. 65-78 (https://dialnet.unirioja.es/ servlet/articulo?codigo $=838059$ ).

Piel, Joseph M. (1948): Nomes de possesores latino-cristãos na toponimia asturo-galego-portuguesa (sep. de Biblos 23), Coimbra, Coimbra Editora.

Pina Polo, Francisco (2004): «Deportaciones como castigo e instrumento de colonización durante la República romana: el caso de Hispania», en Marco Simón, Francisco, Pina Polo, Francisco, y Remesal Rodríguez, José (coords.), Vivir en tierra extraña: emigración e integración cultural en el mundo antiguo. Actas de la reunión realizada en Zaragoza los días 2 y 3 de junio de 2003, Barcelona, Universitat de Barcelona, p. 2II-246.

Pliego V́́zquez, R. (2009): La moneda visigoda, Sevilla, Universidad de Sevilla.

Quirós Castillo, Juan Antonio, y Fernández Mier, Margarita (20I2): «Para una historia social de la arquitectura monumental altomedieval asturiana», en Caballero Zoreda, Luis, Mateos Cruz, Pedro, y García de Castro Valdés, César (eds.), Asturias entre visigodos y mozárabes (Anejos de AEspA 63), Madrid, CSIC, p. 27-53.

Retamero, Félix (2011): «La moneda del Regnum Gothorum (ca. 575-714): una revisión del registro numismático», en Díaz Martínez, Pablo de la Cruz, y Martín Viso, Ińaki (eds.), Between Taxation and Rent. Fiscal 
Problems From Late Antiquity To Early Middle Ages / Entre el Impuesto y la Renta. Problemas de la Fiscalidad Tardoantigua y Altomedieval, Bari, Edipuglia, p. I89-220.

Sánchez de Arza, Vicente (1985): «Sisebuto en Pésicos», Boletín del Instituto de Estudios Asturianos, II4, p. 32I-334.

Sánchez Pardo, Juan Carlos (20I4A): «Organización eclesiástica y social en la Galicia tardoantigua. Una perspectiva geográfico-arqueológica del Parroquial Suevo», Hispania Sacra, 56 (134), p. 439-480

(HтTPs://hispaniasacra.revistas.csic.es/index.php/hispaniasacra/article/ download $/ 423 / 427$ ).

Sánchez Pardo, Juan Carlos (20I4B): «Sobre las bases económicas de las aristocracias en la Gallaecia suevo-visigoda (ca. 530-650 d.C.). Comercio, minería y articulación fiscal», Anuario de Estudios Medievales, 44-2, p. 983-1023

(нттр://estudiosmedievales.revistas.csic.es/index.php/estudiosmedievales/article/view/733/747).

Santiago Fernández, Javier de (20iI): «Legislación y moneda en la Hispania visigoda", Mélanges de la Casa de Velázquez. Nouvelle série, 4I-2, p. 55-74 (https://doi.org/I0.400o/mcv.4008).
Santos Yanguas, Narciso (1997): «Flavionavia, una civitas romana en territorio de los Astures Transmontanos», Espacio. Tiempo y Forma. Serie II. Historia Antigua Io, p. 415-436.

Santos Yanguas, Narciso (1998A): «Flavionavia: una ciudad romana en la frontera del Imperio", Studia historica, Historia antigua, I6, p. I23-I48 (HтTPS://revistas.usal.es/index.php/o213-2052/article/view/6283).

Santos Yanguas, Narciso (1998B): «La inscripción de Ario Sestio hallada en Los Cabos (Pravia) y su posible vinculación con la ciudad astur-romana de Flavionavia», Nuestro Museo: Boletín anual del Museo Arqueológico de Asturias, 2, p. 173-186.

Santos Yanguas, Narciso, y Vera García, Carlos (I999A): «Las acuñaciones monetarias de Pésicos y la conquista de Asturias por los Visigodos", Hispania antiqua, 23, p. 375-400.

Santos Yanguas, Narciso y Carlos Vera García, Carlos (I999b): «Pésicos y las acuñaciones visigodas en Asturias», Numisma, 242, p. 57-80.

Thompson, E.A. (1969): The Goths in Spain, Oxford, Clarendon.

Torres López, Manuel (1963): Las invasiones y los Reinos germánicos de España (años 409-7II), en Menéndez Pidal, Ramón (dir.), Historia de Espańa, Tomo III. Espańa visigoda, Madrid, Espasa-Calpe, p. 3-I40.

VIVEs, JuAn (1942): Inscripciones cristianas de la España romana y visigoda, Barcelona, CSIC 
